\title{
Integrating High Levels of Wind in Island Systems: Lessons from Hawaii
}

\author{
Nicholas Miller ${ }^{1)}$, Devon Manz ${ }^{1)}$, Harjeet Johal ${ }^{1)}$, Sebastian Achilles ${ }^{1)}$, Leon Roose ${ }^{2)}$, James P. Griffin ${ }^{3)}$ \\ ${ }^{1}$ General Electric Company, Schenectady, NY, USA, e-mail: nicholas.miller@ge.com \\ ${ }^{2}$ Hawaiian Electric Company, Honolulu, HI, USA \\ ${ }^{3}$ University of Hawaii, Hawaii Natural Energy Institute, Honolulu, HI, USA
}

\begin{abstract}
Variability of power generation from intermittent resources such as wind and solar plants presents an operational challenge for grid operators. The economic incentives and technical challenges that accompany large amounts of variable generation in island power systems are often much greater. The Hawaiian Electric Company and its subsidiaries, the Maui Electric Company and the Hawaii Electric Light Company have considerable experience in planning and operating power systems with relatively high levels of wind power. The islands of Hawaii and Maui operate power systems with high levels of wind power (more than $10 \%$ by energy) and have experienced and addressed challenges associated with the variability and uncertainty of wind power. The island of Maui is anticipating further wind plant deployments in the near future. Recent analyses of possible near-term deployment of large amounts of wind power on the Oahu power system $(500 \mathrm{MW}$ of wind power; approximately $1200 \mathrm{MW}$ peak and 520MW minimum annual load) has shown the potential for this system to accept almost $25 \%$ of its energy from wind and solar power. This paper will identify some of the wind integration challenges and highlight the benefits of a variety of strategies that are expected to improve system economics and operational reliability, including proposed modifications to the baseload thermal fleet (deeper turndown, higher ramp rates, and tuned droop characteristics), advanced wind turbine grid support features, new operating strategies, wind forecasting and refinements to the up and down reserve requirements. This paper will present the key findings in the context of useful insights and lessons learned that are relevant to other island power systems considering very high levels of wind power.
\end{abstract}

Index Terms - wind energy, power systems, power generation dispatch, power system stability, power system control

\section{INTRODUCTION}

In 2008 the Hawaiian Electric Company (HECO) and the State of Hawaii signed the Energy Agreement. The Energy Agreement is part of the State's energy policy and documents a course of action to reduce Hawaii's dependence on imported fossil fuels and develop indigenous renewable energy sources. To that end, the Energy Agreement commits Hawaiian Electric to facilitate the integration of substantial amounts of wind and other renewable energy into its grid and to enable electricity consumers to manage their electricity use more effectively. In this agreement, the renewable portfolio standard (RPS) goals were modified to require $40 \%$ of the islands electricity be generated from renewable energy by 2030 (10\% by $2010,15 \%$ by 2015 , and $25 \%$ by 2020$)$, which is one of the highest standards in the nation.

The General Electric Company, the Hawaii Natural Energy Institute, and the Hawaiian Electric Company set forth to develop detailed, state-of-the-art power systems models of the Oahu grid spanning many timescales of power system operation from seconds to one year. The Oahu power system was modeled in GE Multi-Area Production Simulation (GE MAPS $^{\mathrm{TM}}$ ) and GE Positive Sequence Load Flow (GE $\mathrm{PSLF}^{\mathrm{TM}}$ ). In addition to these tools, new tools were developed to assess the sub-hourly system performance; a critical timeframe on island power systems with high levels of wind power. Additional tools were used to assess the ramp rate and reserve adequacy of the Oahu system (GE Interhour Reserve Adequacy Tool) as well as the system frequency performance during specific, challenging events (GE Automatic Generation Control Model). All together, these tools were used to identify system performance and characteristics, such as unit commitment and dispatch, amount of wind energy curtailed, total variable cost, thermal unit ramp rate adequacy, frequency performance during challenging system events, transient frequency performance for relevant high wind contingencies, etc. Following this assessment a number of potential strategies were considered to improve system operation, reliability and economics. In parallel with this effort, the Hawaiian Electric Company performed a number of internal studies ranging from capability assessments of steam generator improvements, EMS/AGC, fast-start generation, load control as an operational resource, wind resource modeling, and wind forecasting potential. The results of these assessments were used in this study. Also in parallel, a number of large studies were undertaken including a technical undersea HVDC cable feasibility assessment and a variety of other systems studies. The results presented incorporate the conclusions and recommendations of many of these studies.

\section{SYSTEM DESCRIPTION}

A model of the Oahu power system was developed for the scenario year of 2014. The system peak load for this year is projected as $1243 \mathrm{MW}$ and the minimum load as 513MW, 
with a total annual energy consumption of 7800GWh. The Oahu system is comprised of a $138 \mathrm{kV}$ transmission network and $46 \mathrm{kV}$ sub-transmission system. In this study, wind plants located on Oahu and the neighboring islands of Molokai and Lanai were studied. The wind plants situated on Molokai and Lanai were electrically connected to Oahu via a proposed HVDC cable system. A schematic is shown in Figure 1.

Oahu

100MW Wind

100MW PV

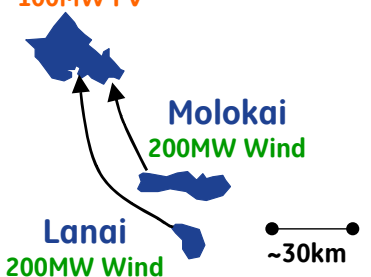

Figure 1 - Illustrative schematic of the Oahu and undersea cables to Molokai and Lanai

The connection of the small local loads on the islands of Molokai and Lanai (annual peak demand of approximately 5MW on each of the islands) was not considered in the study. The Hawaiian Electric Company, the State of Hawaii, and others are presently studying the cable configuration, sizing and control of this HVDC connection.

HECO operates a fleet of steam turbines and combustion turbines. Independent power producers provide energy to HECO from coal, waste-to-energy and residual fuel oil. The modeled generation fleet for the study year 2014 is shown in Table I. A week of operation is shown for the Baseline 2014 system in Figure 2. This is one week of power production from the generating units shown in

TABLE I

SUMMARY OF GENERATING UNITS

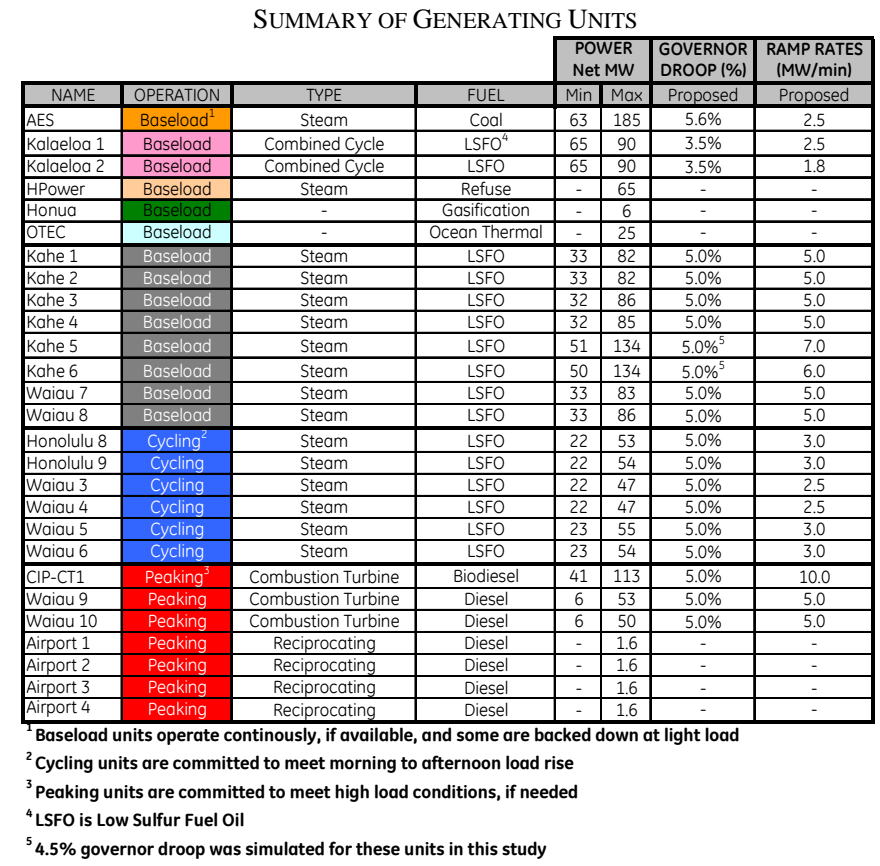

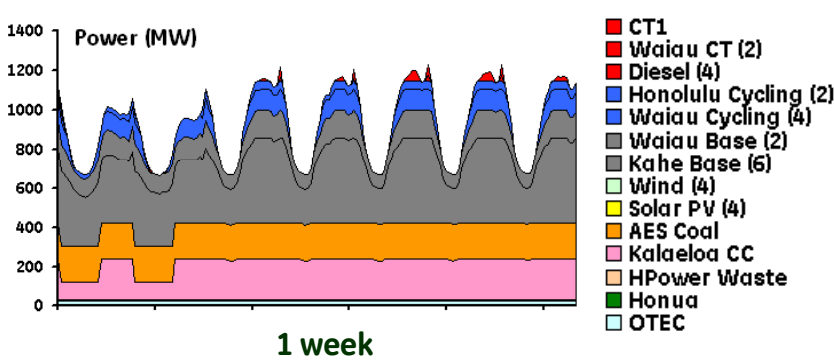

Figure 2 - Seven days of operation of the Oahu Baseline 2014 system

Baseload energy is provided by the Kalaeloa combined cycle plant, HPower waste-to-energy plant, AES coal steam plant, six HECO steam units at Kahe and two HECO units at Waiau. On the first two days of the week shown in Figure 2 the Kalaeloa combined cycle plant operates in single-train as part of a plant washing schedule. A small amount of baseload energy is also provided by Honua (gasification unit) and OTEC (ocean thermal) plants; both assumed to be deployed in 2014. HECO cycling units at Honolulu and Waiau are dispatched during the daily load rise. If needed, the combustion turbines at Waiau and Campbell Industrial (CT1, new unit to be deployed by 2014) are dispatched to meet peak load.

Figure 3 shows the annual energy production by unit type for the Baseline 2014 system. The eight HECO baseload units at Kahe and Waiau and the two large IPP plants (AES coal steam plant and Kalaeloa Combined Cycle Plant) provide the majority of the island's energy. The cycling units are dispatched during days when the peak load is relatively high; while the peaking units are dispatched for a small number of hours when multiple baseload units are on outage and/or the available cycling units cannot meet the peak load.

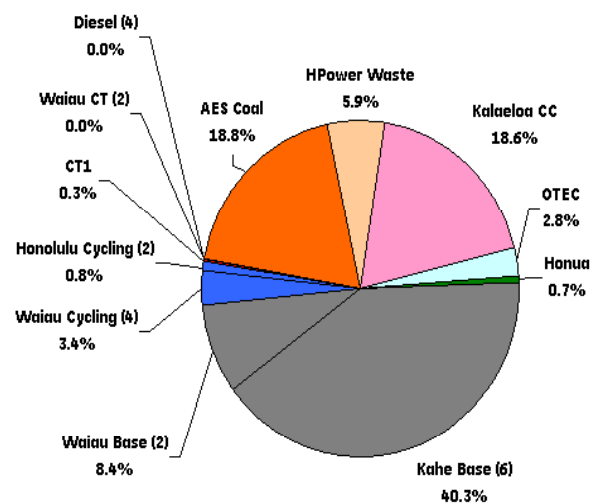

Figure 3 - Summary of annual energy production; Baseline 2014 system

\section{SYSTEM DESCRIPTION}

Three primary scenarios were considered; each examining a staged approach of integrating wind power on the Baseline 2014 Oahu system. The primary scenarios discussed in this paper are presented in Table II.

It was assumed that 100MW of solar power (comprised of both distributed and centralized PV) was deployed in each scenario. Concentrating solar thermal power was not considered in this study. Lack of available solar data did not permit a detailed analysis of solar power to the extent it may be necessary for integration of this large amount of PV, relative to system load. 
TABLE II

OAHU WIND INTEGRATION STUDY SCENARIOS

\begin{tabular}{|l|c|c|c|c|c|}
\hline \multirow{2}{*}{ Scenario } & \multirow{2}{*}{ Title } & \multicolumn{3}{|c|}{ Wind } & Solar PV \\
\cline { 3 - 6 } Baseline & 2014 Baseline & - & - & - & - \\
\hline Scenario \#1 & $\begin{array}{c}\text { "Big Wind" } \\
\text { Oahu only }\end{array}$ & $100 \mathrm{MW}$ & - & - & $100 \mathrm{MW}$ \\
\hline Scenario \#2 & $\begin{array}{c}\text { "Big Wind" } \\
\text { Oahu + Lanai only }\end{array}$ & $100 \mathrm{MW}$ & $400 \mathrm{MW}$ & - & $100 \mathrm{MW}$ \\
\hline Scenario \#3 & $\begin{array}{c}\text { "Big Wind" } \\
\text { Oahu + Lanai + } \\
\text { Molokai }\end{array}$ & $100 \mathrm{MW}$ & $200 \mathrm{MW}$ & $200 \mathrm{MW}$ & $100 \mathrm{MW}$ \\
\hline
\end{tabular}

The scenario analysis begins with understanding the effect of integrating 100MW of on-island wind and 100MW of solar power on Oahu (Scenario 1). Scenario 2 adds 400MW of offshore wind from the island of Lanai to the Oahu grid (representing no site diversity of the off-island wind resource). Finally, Scenario 3 studies the effects of equally distributing the off-island wind energy between Lanai and Molokai, thus examining the effects of greater geographic diversity of the wind resource.

Five primary tools were used in this study. The first two tools are conventional power system tools that were enhanced and refined for this study based on the need to more accurately reflect the operation of each unit; an important requirement for an electrically small, island power system:

1. GE Multi-Area Production Simulation (GE MAPS ${ }^{\mathrm{TM}}$ ) Production Analysis

a. Assess unit-by-unit commitment and dispatch, and energy production, wind curtailment, fuel consumption, emissions, and variable cost of operation.

(1-hr time steps for 1-yr of operation)

2. GE Positive Sequence Load Flow (GE PSLF ${ }^{\mathrm{TM}}$ ) Transient Stability Analysis

a. Assess unit-by-unit response and system frequency and voltage performance during contingency events.

(200-ms time steps for 1-min)

3. GE Interhour Tool

Ramp Rate and Reserve Adequacy Analysis

a. Screen GE MAPS ${ }^{\mathrm{TM}}$ results for windows of interest to be analyzed in GE PSLF ${ }^{\mathrm{TM}}$ Long-

Term Dynamic Simulations, and

b. Assess the reserve and ramp rate capability of generation to respond to sub-hourly wind, solar, and load changes based on the dispatch from GE MAPS ${ }^{\mathrm{TM}}$.

(10-min time steps for 1-yr)

4. GE Positive Sequence Load Flow (GE PSLF ${ }^{\mathrm{TM}}$ ) Long-Term Dynamic Simulations

a. Assess frequency performance and unit-byunit response during wind power variability events that sustain for seconds to one hour.

Simulations reflect representative Automatic Generation Control (AGC) operation and governor characteristics of each unit (2-sec time steps for 1-hr).

5. Statistical Wind Power Variability Assessments Data Benchmarking a. Assess wind power statistics as well as benchmark wind power data against historical production data.

The study begins with the GE MAPS ${ }^{\mathrm{TM}}$ production cost simulations, which steps through a year in one-hour time steps; committing and dispatching the generating units based on the wind forecast, reserve requirements, and load forecast, while respecting system constraints, including the transmission infrastructure. The results of these simulations provide the wind/solar curtailment, starts/stops by unit, operating hours by unit, and the total variable cost of operation. Each generating unit is modeled in GE MAPS ${ }^{\mathrm{TM}}$ (max MW, min MW, heatrate, O\&M cost, start-up cost, minimum up time/down time, etc). For the sub-hourly timeframe, tools were enhanced (GE Interhour Tool and the GE Long-Term Dynamic Simulation Tool) to assess the adequacy of the up and down reserve of the system, respecting the ramp rate capabilities of the thermal unit, the behavior of the Automatic Generation Control (AGC) and the governors of the thermal units. Finally, GE PSLF ${ }^{\mathrm{TM}}$ Transient Stability Analysis Tool was used to analyze the system frequency and voltage during certain challenging system events (contingencies). These tools were used together to assess system performance and provide insight into the system reinforcements needed to accept such high levels of wind power.

\section{WIND POWER VARIABILITY}

Wind power variability challenges the ability of the system to meet the load at all times. It thus becomes imperative to understand wind variability in different timescales (hours, minutes, seconds) in order to assess the impact of higher levels of wind power penetration.

The number, size and geographic diversity of wind plants affect the variability of wind power production as seen by the power system. Large wind plants that are spread over a vast distance exhibit lower levels of sub-hourly variability (on a per unit nameplate basis) as compared to smaller wind plants situated near one another. Since there will be relatively few wind plants and these plants will be geographically close to one other, the variability of wind power delivered to the Oahu system will be much higher than what would be observed in a larger balancing area.

AWS Truepower provided two years of modeled wind power data for the wind plants considered in this study. Both 2-second and 10-minute wind power data were provided. Figure 4 shows a histogram of the total hourly wind power production changes in Scenario 3 (200MW Lanai, 200MW Molokai, 100MW Oahu) for the year 2007 and 2008.

The largest 60-min wind power change (negative most in Figure 4) was observed to be $311 \mathrm{MW}$ in Scenario 3. A 5\% loss of wind energy through the HVDC cable system was assumed for the energy delivered to Oahu from the Molokai and Lanai wind plants. The largest total wind power reduction over a 10-minute interval was observed to be 90MW in Scenario 3 (and 127MW in Scenario 2).

Large wind power variability events over 10-min and 60min, and the system condition (load, commitment, and dispatch) during these events were of interest for planning purposes. The system performance during these particular times was analyzed in the dynamic simulation tools and will be discussed later. 


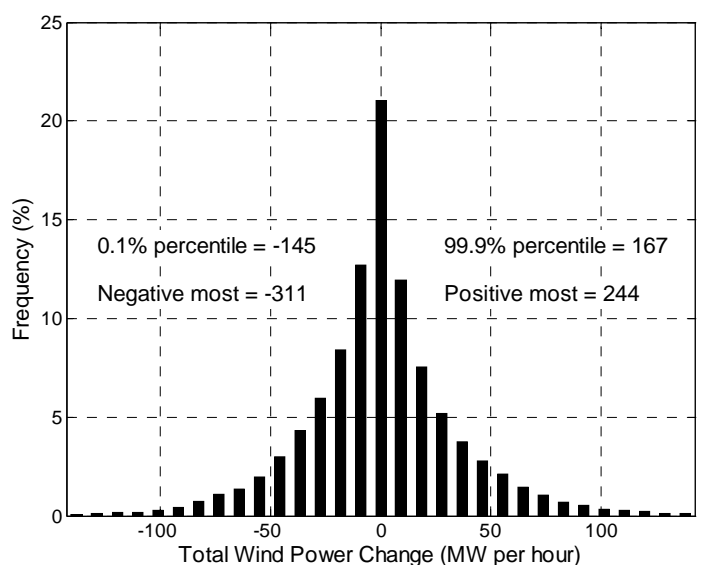

Figure 4 - Histogram of total wind power changes over 60-minutes for Scenario 3 (two years of simulated wind power from AWS Truepower).

\section{Wind POWER ForecAsting AND RESERVE STRATEGIES}

Wind power forecasts (1hr, 4hr, 6hr, 24hr ahead) were provided by AWS Truepower for each wind plant. For this study, 4-hr ahead wind power forecast was considered in the unit commitment because this provided an adequate amount of time for the Hawaiian Electric Company (HECO) to commit additional cycling units to meet the residual load if wind power is forecasted to drop.

The Oahu power system maintains 185MW of spinning reserve to cover for loss of the largest unit, the AES coal plant. In addition to the spinning reserve, the study examined increasing the amount of reserve on the system by an amount that would capture the sub-hourly wind variability. This additional component of reserve is needed to support the system during the times when wind power rapidly decreases before another unit can be started. One approach considered all of the wind power drops over 10-min intervals for two years of wind power data. All of these events are shown in Figure 5 as a function of the total wind power production at the start of each 10-min interval.

The wind power drops are relatively modest at both high and low levels of wind power production. At these levels of wind power production, a change in wind speed has a moderate affect on overall wind power changes. In contrast, at mid-range production levels, the same change in wind speed can result in larger changes in wind power. This is observed in Figure 5. It was decided by the team that in addition to the $185 \mathrm{MW}$ of spinning reserve, the Oahu system would also carry an additional up reserve based on the red curve shown in Figure 5. This was done to ensure that sufficient up reserves were available to manage feasible 10min drops in wind power. The decision of choosing a 10-min interval, instead of a 60-min interval was based upon the faststarting capability of some HECO units. The "fast-starting" generation could be brought on-line in less than an hour during relatively large wind power drop events. The 4hrahead wind power forecast was used in both the unit commitment and in specifying the up reserve requirement based on the equation shown in Figure 5. It should also be noted that since the baseload thermal units (AES Coal, Kalaeloa Combined Cycle, Waiau Steam and Kahe Steam) are backed down at light load, there is significant up reserve in excess of the requirement during these times.

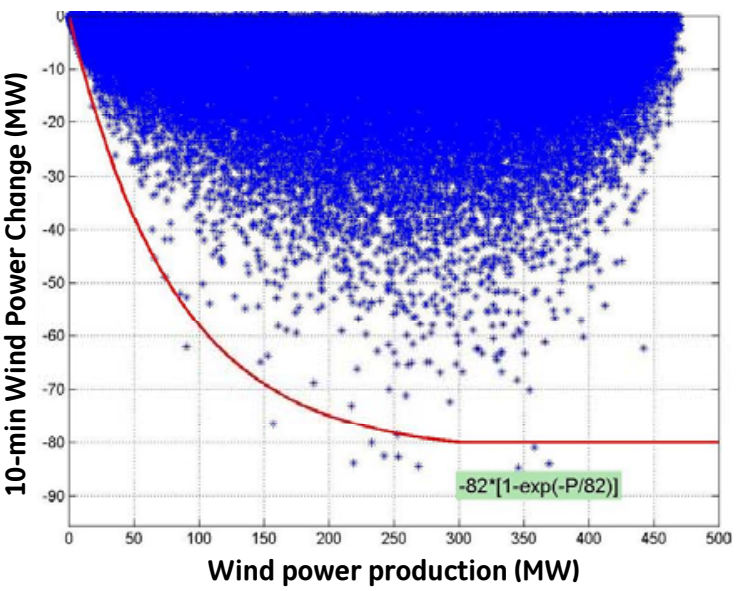

Figure 5 - Total wind power changes over 10-min intervals in Scenario 3 (two years of simulated wind power data from AWS Truepower).

\section{SYSTEM DYNAMICS}

The sub-hourly system dynamics was considered in order to assess the stability of operations under challenging system events and during times when the Oahu system may be most vulnerable. A variety of dynamic events were considered to understand the mitigation strategies or system reinforcements that may be required. The critical events examined include:

1. Sustained wind power drops over one hour Potentially challenge the system's up reserve

2. Sustained wind power drops within an hour Potentially challenge the up ramp rate capability of the thermal units

3. Volatile wind power changes Potentially challenge the maneuvering capability of thermal units

4. HVDC cable trip contingency event Potentially cause large under-frequency events

5. Load rejection contingency event Potentially cause large over-frequency events

Each of these dynamic events will be described in the following sections.

\section{A. Sustained wind power drops over one hour}

The largest wind power drop in all scenarios was observed in Scenario 3. At $2 \mathrm{pm}$ on October $13^{\text {th }}$, in the future study year, the load was $1160 \mathrm{MW}$ and the wind power dropped by a total of $311 \mathrm{MW}$ over a 60 -min interval (27\% loss of generation), challenging the systems' up reserve. At the completion of this one-hour event, if no new units were dispatched, only 5MW of up reserve remained on the system, which is significantly less than the $185 \mathrm{MW}$ spinning reserve requirement. In the following hour, fast-start units would be dispatched in order to return the system to the appropriate level of up reserve. The wind drop event is shown in Figure 6. The legend is the same as shown in Figure 2. The wind and solar power drop over this hour, and the associated frequency performance is shown in Figure 7. The system frequency was manageable for this event.

Note that limited solar power data were available. Solar power data was contributed by a team from the National Renewable Energy Laboratory (NREL) based on kW-scale PV installations on Oahu. It was assumed that 100MW of solar power (both distributed and centralized PV) was 
deployed in each scenario primarily to evaluate its impact on wind energy delivered to the Oahu system.

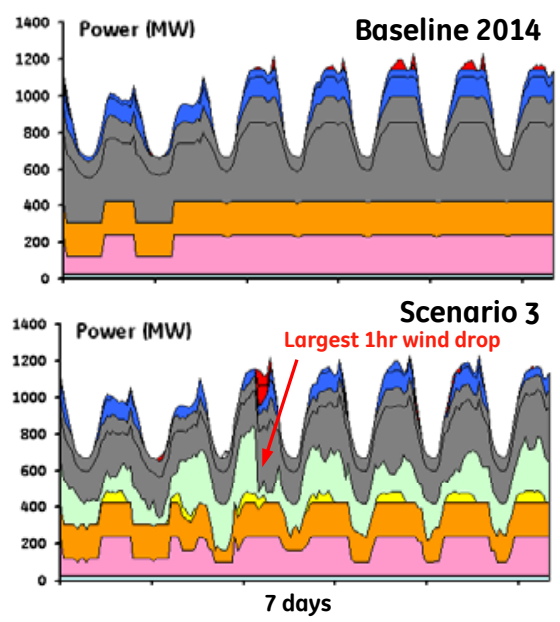

Figure 6 - Week containing the largest hourly wind power drop. Legend is provided in Figure 2.
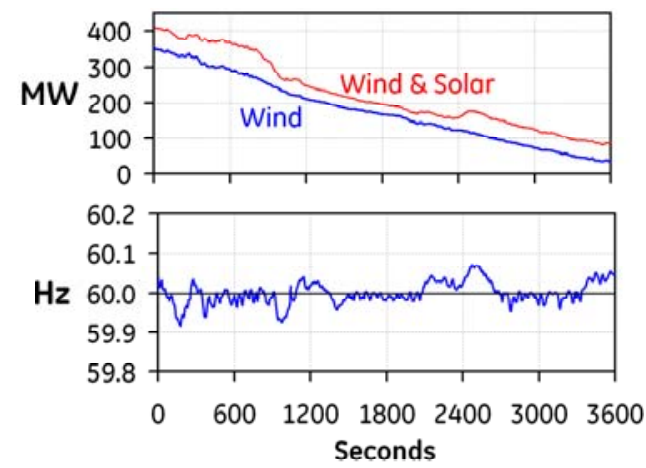

Figure 7 - Frequency performance during largest 60-min wind power drop

\section{B. Sustained wind power drops within an hour}

The screening process revealed the hour of August 30th at $10 \mathrm{am}$ in Scenario 3, in the future study year. During this wind variability event, the ramp rate capability of the thermal units was challenged by the wind, solar and load change over a 10min interval. The load was $1108 \mathrm{MW}$ when the wind dropped by $83 \mathrm{MW}$, the solar dropped by $16 \mathrm{MW}$ and the load increased by $6 \mathrm{MW}$; all over $10-\mathrm{min}$. The proposed future HECO thermal unit AGC ramp rate capability is shown in Table I. It was shown that if Kahe 6 was not on AGC, the present HECO thermal unit ramp rates and governor droop characteristics would not be sufficient to avoid triggering under-frequency load shedding during this event. In Figure 8, the frequency response during this hour is presented for two cases. The top figure highlights the frequency response of the system if today's thermal unit ramp rates and droop characteristics were implemented. The frequency reaches the UFLS at $59.5 \mathrm{~Hz}$. The bottom figure highlights the frequency response of the system if the proposed future thermal unit ramp rates and droop characteristics were implemented. The frequency remains relatively stable. Therefore, if the HECO thermal unit ramp rates and droop characteristics were improved to the proposed values as shown in Table I, the frequency performance would be manageable for this event. More aggressive ramp rates and droop were needed to avoid under-frequency load shedding.
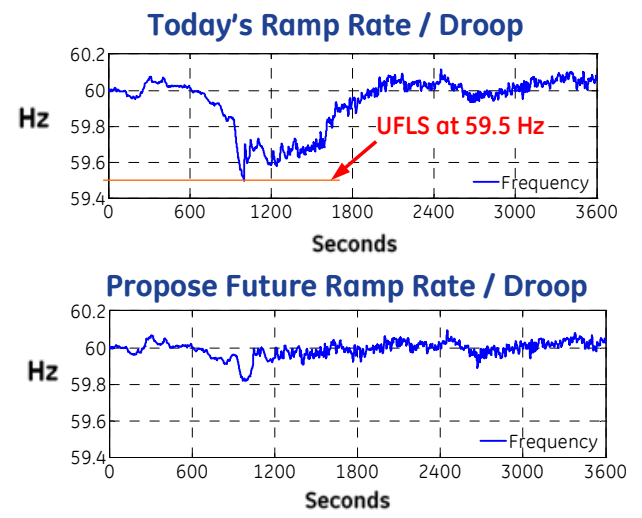

Figure 8 - Large wind, solar, load change over 10-min that challenged the system ramp rate capability

\section{Volatile wind power changes}

A screening process was performed to identify large changes in wind power over 5 to 10 -min intervals. The screening process revealed the hour on August $30^{\text {th }}$ at $10 \mathrm{am}$ in Scenario 5, in the future study year, when the load was 995MW. This event was considered in the simulation tools to determine whether the additional maneuvering of the thermal units caused by wind power changes could be accommodated. The power output from each unit was assessed by the HECO team to determine if the maneuvering could be accommodated.
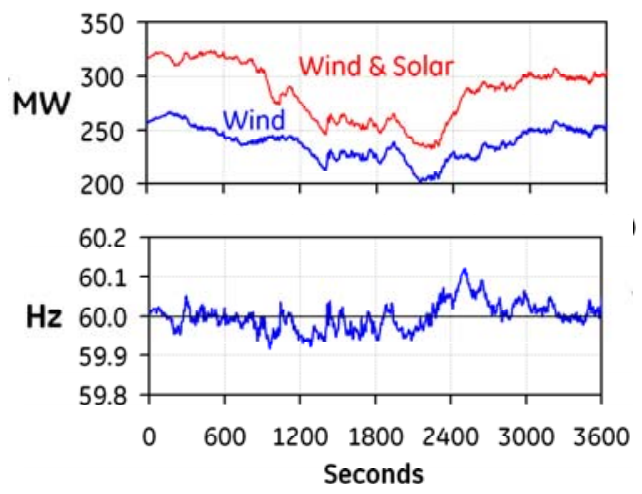

Figure 9 - Large changes in wind power in both directions

The frequency performance was manageable for this event. Improving the ramp rates and droop eliminated some of the fast-frequency variations. The observed thermal unit maneuvering was deemed to be within acceptable limits by HECO. Of the eight HECO baseload units and two IPPs that provide regulation, it was observed that the HECO baseload units provided most of the response during these wind variability events, largely because they are backed down and are providing most of the up reserve for the Oahu system.

\section{HVDC cable trip contingency event}

On October $28^{\text {th }}$ at $8 \mathrm{pm}$, in the future study year, the load was $1020 \mathrm{MW}$ and the delivered wind was 363MW in Scenario 3. The up reserve was relatively low at 267MW; a unit was about to be committed to increase the system up reserve. It was assumed that at that instant, 200MW of the 282MW of wind power coming from the off-island wind plants situated on Lanai and Molokai was tripped. This event resulted in a substantial frequency sag that triggered $\sim 55 \mathrm{MW}$ of load shedding. After one of the two off-island wind plants trips, the frequency sagged (blue curve in Figure 10). For this case, wind plant inertial response was considered to help 
mitigate the frequency drop associated with the trip of one of the wind plants. Details of the wind plant inertial response can be found in [1]. When enabled with inertial response, the remaining $163 \mathrm{MW}$ of wind power (82MW from off-island and $81 \mathrm{MW}$ from on-island) helped reduce the minimum frequency sag by $13 \mathrm{mHz}$ (difference between the blue curve and the red curve in Figure 10). The inertial response from the un-tripped wind plants significantly improved the frequency performance during this cable trip event.

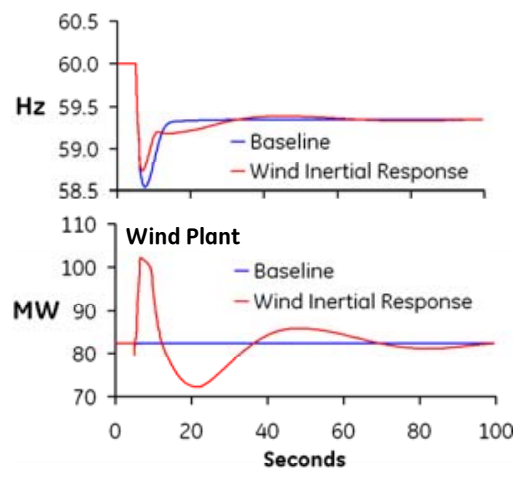

Figure 10 - 200MW cable trip event in Scenario 3 with future thermal unit droop characteristics, with and without wind turbine inertial response. Bottom figure shows response from remaining off-island wind plant.

\section{E. Load rejection contingency event}

For the high levels of wind power simulated for Scenarios 2 and 3, the thermal units are backed down to lower operating power to accept the wind energy. When more wind energy is available, the thermal units will be further backed down. The wind energy can only be accepted until the thermal units are backed down to their minimum dispatchable power respecting the down reserve requirement on the system. It is necessary to maintain an adequate level of down reserve to ensure that the units remain at a stable operating power during typical load rejection events. Figure 11 compares one week of production output for the Baseline 2014 case and Scenario 3. This week corresponded to the week of largest available wind power. It is evident that during this week the baseload thermal units operate for many hours backed down to lower power levels as compared to the Baseline 2014 system.

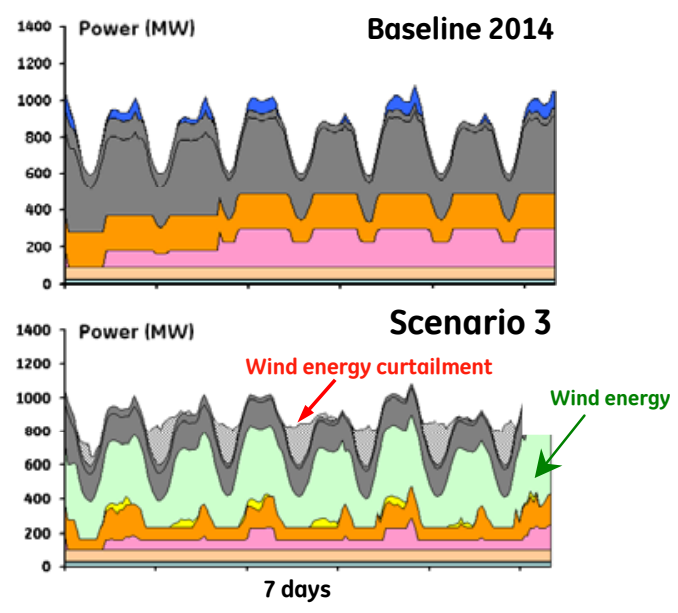

Figure 11 - Week of highest available wind power in Scenario 3

Wind energy curtailment occurs when the thermal units are against the down reserve requirement and additional wind energy is available. At the level of wind power considered in Scenarios 2 and 3, the thermal units will spend many more hours operating backed down. According to Table III some of the HECO baseload units operate for more than twice as many hours at their dispatchable minimum power (respecting the down reserve requirement) as compared to the Baseline 2014 case. Based on the fuel price assumptions for this study, AES and Kalaeoloa are lower cost units than the HECO steam units, so AES and Kalaeloa operate many fewer hours at minimum power as compared to the HECO baseload units.

TABLE III

Operation at Minimum DisPatChable POWER (\% WITH RESPECT TO BASELINE 2014 CASE)

\begin{tabular}{|c|c|c|c|c|}
\hline \multirow{2}{*}{$\begin{array}{l}\text { Time at minimum } \\
\text { dispatchable power }\end{array}$} & \multicolumn{4}{|c|}{ SCENARIO } \\
\hline & Baseline & 1 & 3 & 5 \\
\hline Kahe 1 & $100 \%$ & $134 \%$ & $153 \%$ & $158 \%$ \\
\hline Kahe 2 & $100 \%$ & $143 \%$ & $173 \%$ & $173 \%$ \\
\hline Kahe 3 & $100 \%$ & $139 \%$ & $225 \%$ & $228 \%$ \\
\hline Kahe 4 & $100 \%$ & $134 \%$ & $159 \%$ & $160 \%$ \\
\hline Kahe 5 & $100 \%$ & $140 \%$ & $261 \%$ & $261 \%$ \\
\hline Kahe 6 & $100 \%$ & $131 \%$ & $273 \%$ & $272 \%$ \\
\hline Waiau 7 & $100 \%$ & $137 \%$ & $93 \%$ & $92 \%$ \\
\hline Waiau 8 & $100 \%$ & $129 \%$ & $145 \%$ & $146 \%$ \\
\hline
\end{tabular}

With the thermal units operating at lower power during many more hours of the year, the system will be more susceptible to a load rejection event that could put the system at risk unless an appropriate down reserve is maintained. This contingency was considered in the dynamic analysis.

On October $23^{\text {rd }}$ at $12 \mathrm{am}$, in the future study year, the load was $720 \mathrm{MW}$. At this instant a $140 \mathrm{MW}$ load rejection event was simulated. The wind power was providing approximately $50 \%$ of the generation (357MW) and many of the units were dispatched at their minimum dispatchable power. At this instant the system was carrying 89MW of down reserve. The over-frequency response is shown in Figure 12.

The frequency excursion is significantly reduced when the wind plants contribute to an over-frequency event by rapidly reducing their power production, as shown in Figure 12, when the wind plants transiently reduce their output (red trace in Figure 12). Since the system will operate for many more hours with the thermal units backed down as compared to the Baseline case, there will be more hours when the system would be at risk of these types of events. This wind turbine feature can help to maintain a more stable system frequency during these types of events. In addition, a consequence of increased operation at low load is lower thermal efficiency (higher average heat rate).

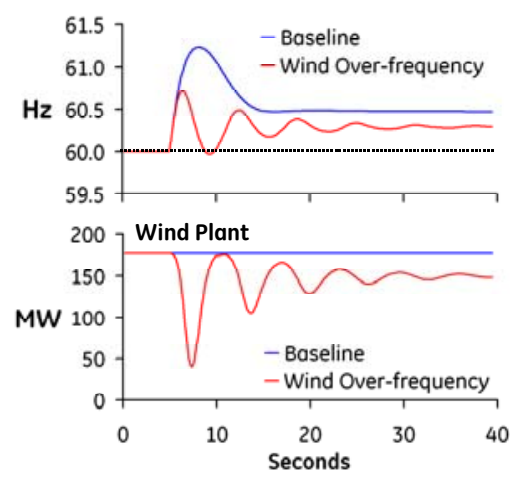

Figure 12 - 140MW load rejection in Scenario 3 with future thermal unit droop characteristics, with \& without wind turbine over-frequency control. 


\section{RESULTS}

The results of this study suggest feasible operation of the Oahu power system with high levels of wind and solar power (26\% by energy, $50 \%$ installed nameplate wind and solar power relative to peak load). The annual energy production by fuel type is shown in Figure 13. This study also suggests changes to present operational practices and other system modifications to enable the operation of the grid with such high renewable penetration.

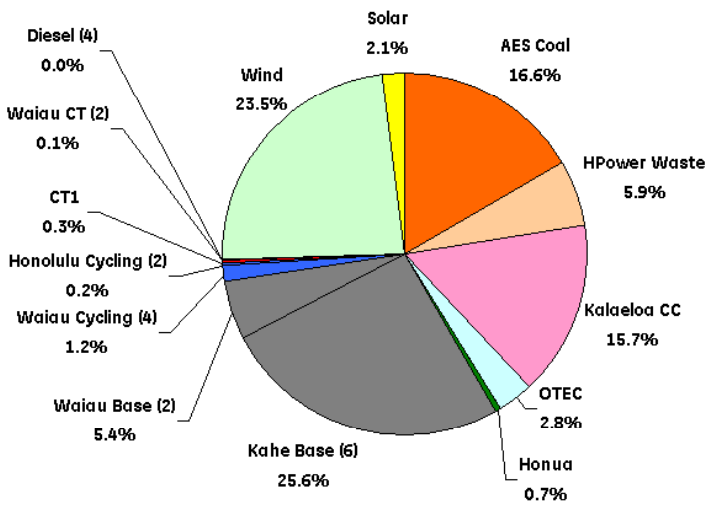

Figure 13 - Annual energy production by fuel/unit type for Scenario 3

The system modifications proposed in this study are:

A. Strategy \#1: Wind power forecast and up regulation requirement

- Incorporate state-of-the-art wind power forecasting in the unit commitment, and

- Increase up reserve requirement based on the strategy described in Figure 5 to help manage subhourly wind variability,

This strategy increased the wind energy delivered by 7\%, by reducing the wind energy curtailment, and reduced the annual variable cost by $4 \%$.

B. Strategy \#2: Reduce thermal unit minimum power and specify down reserve requirement

- Reduce the minimum stable operating power of seven HECO baseload units by a total of $130 \mathrm{MW}$,

- Implement a down reserve requirement (modeled as effectively 90MW) to address plausible load rejection events.

These strategies further increased the wind energy delivered (to 14\% with respect to Scenario 3 without modifications) and further decreased the annual variable cost (to $9 \%$ with respect to Scenario 3 without modifications). Note that cycling off a single baseload unit at a time for a total of 18-weeks during the year was included in this strategy, but only had a small effect on increasing the delivery of renewable energy and negatively effected the total variable cost of operation since energy from the more expensive cycling units was needed during these 18-weeks.

C. Strategy \#3: Refine up reserve requirement to include other resources that can provide reserve

- $\quad$ Reduce on-line regulating reserves necessary to meet up reserve by leveraging other resources, such as fast-start units and load control programs.

Modifying the up reserve requirement did not further increase the wind energy delivered, but did reduce the variable cost by a total of $10 \%$.

\section{Strategy \#4: Improve system performance}

To ensure the above scenario is operable through the dynamic events considered in the study, the following is needed to help improve system operation with high levels of wind power:

\section{Wind Plants \& HVDC cable}

- Deploy wind plants capable of providing: (1) inertial response for significant under-frequency events, (2) frequency control for significant over-frequency events, (3) less than 10-min response to curtailment requests, and (4) wind plant under-frequency control during periods of curtailment due to other system needs.

- Ensure undersea cable project is capable of providing performance of off-island wind plants on Oahu.

2. Thermal Unit Modifications

- Increase ramp rates of HECO thermal units, and

- Enhance droop characteristics of HECO thermal units.

3. Operating Strategies

- Continuously monitor wind power variability and wind forecast accuracy to improve reserve and forecasting,

- Implement severe weather monitoring to ensure adequate unit commitment during periods of high wind variability,

- Continuously monitor and report fast-start capacity and load control available,

- $\quad$ Once wind plants are in operation, further refine down reserve requirement based on actual wind plant overfrequency performance during load rejection events, and,

- Integrate wind power measurements, automatic wind curtailment and allocation in system operating practices.

Each successive strategy helped to reduce the annual variable cost and increase the amount of wind energy delivered. With these approaches the level of wind energy curtailment was reduced from $17 \%$ to $5 \%$ of the total wind energy available on the island of Oahu. The results are shown for Scenario 3 in Figure 14.

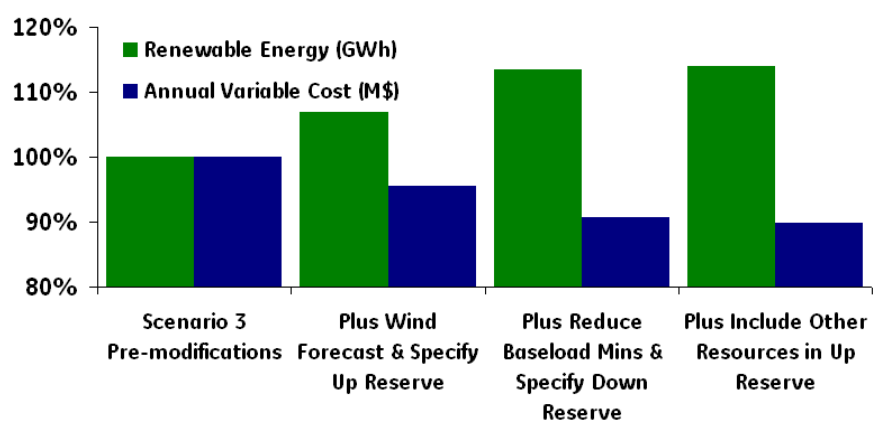

Figure 14 - Scenario 3. Reduction in variable cost and increase in wind and solar power delivered as a result of three strategies

The results of the study can also be used to help assess the economic viability of the proposed system modifications. The total variable cost reduction between the Baseline 2014 Scenario and any of the other Scenarios represents the savings in O\&M, start-up, and fuel cost. The total annual variable cost is shown in Figure 15 for each scenario. Scenario 3 has a slightly lower cost of operation than Scenario 2, which is attributed to the fact that geographical diversity of wind resources requires smaller amount of regulating reserves to counteract wind variability. 


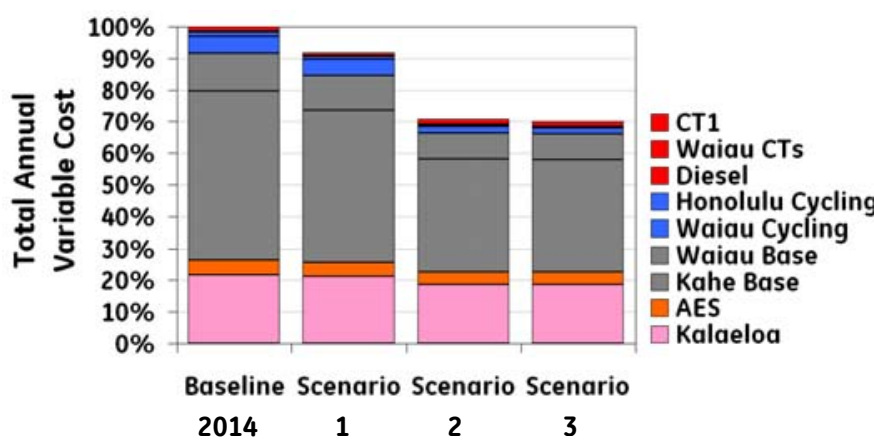

Figure 15 - Total annual variable cost of operation. Cost of HPower, Honua, OTEC, wind, and solar power are excluded.

The difference in height between each bar in Figure 15 represents the total annual variable cost savings that can be used to purchase wind and solar power as well as to cover the costs of the necessary system modifications in order to accept this level of variable renewable energy The proposed modification that will reduce the minimum operating power of some HECO thermal units will improve the efficiency of these units in the lower part of their operating range; this will improve the value beyond what is shown in Figure 15. The results (summarized in Table IV) highlight that 500MW of wind power and 100MW of solar power supplied almost $25 \%$ of the island's energy needs, enabling Oahu to reduce its annual fuel consumption by almost 20 million MMBtu.

\begin{tabular}{|c|c|c|c|c|c|c|c|c|}
\hline & \multicolumn{3}{|c|}{ Installed Wind (MW) } & \multicolumn{3}{|c|}{ Wind Energy (GWh / yr) } & \multirow{2}{*}{$\begin{array}{c}\text { Total Fuel } \\
\left(10^{6} \mathrm{MMBtu} /\right. \\
\mathrm{yr})\end{array}$} & \multirow{2}{*}{$\begin{array}{l}\text { Total Annual } \\
\text { Variable Cost }\end{array}$} \\
\hline & Oahu & Molok ai & Lanai & Available $e^{1}$ & Delivered & Curtailed & & \\
\hline Baseline 2014 & 0 & 0 & 0 & 0 & 0 & 0 & 81.3 & $100.0 \%$ \\
\hline Scenario 1 & 100 & 0 & 0 & 358 & 358 & 0 & 76.0 & $91.7 \%$ \\
\hline Scenario $2+$ Strategies & 100 & 0 & 400 & 1,914 & 1,815 & 99 & 61.3 & $70.9 \%$ \\
\hline Scenario 3 & 100 & 200 & 200 & 1,929 & 1,595 & 334 & 62.2 & $77.9 \%$ \\
\hline Scenario $3+$ Strategies & 100 & 200 & 200 & 1,929 & 1,839 & 90 & 61.0 & $70.0 \%$ \\
\hline
\end{tabular}

\section{CONCLUSIONS}

Most power systems can rely on neighboring control areas to help balance the uncertainty and variability of wind power production. On island systems this is not an option. Since the system must precisely balance the load and generation, it was necessary to develop detailed, state-of-the-art power systems models of the Oahu system spanning a wide range of timescales. This was needed to accurately identify the gchallenges associated with integrating high levels of wind power and assess system modifications to help manage these challenges. The results of this study and the approach presented can offer a framework for other island power systems or isolated power systems preparing to accommodate very high levels of wind power.

Integrating high levels of renewable energy into an island power system challenges the reliability and stability of the grid. This study has helped HECO assess the performance impacts of renewable energy on the island of Oahu. This work has also helped HECO lay a framework for assessing a variety of proposed system modifications and alternatives that could be used to accommodate the near-term wind plant deployments studied in this effort.

This analysis suggests that the Oahu system can accommodate the wind and solar projects examined in this study, with the operational and equipment modifications described above, to enable almost $25 \%$ of its energy from wind and solar power. Reliable operation with the projects examined in this study will require investment in existing and new infrastructure, as well as specific requirements on the wind plants to be connected to the Oahu system.

\section{ACKNOWLEDGMENT}

The authors would like to acknowledge the support of the Department of Energy, the Hawaii Natural Energy Institute, and the Hawaiian Electric Company. The authors would like to recognize the following team members for their contributions: Dean Arakawa, Marc Matsuura, Robert Young, Dora Nakafuji, Terry Surles, Rick Rocheleau, Wei Ren, Krishna Anaparthi, Shakeer Meeran, and Gene Hinkle.

\section{REFERENCES}

[1] N. Miller, K. Clark, R. Walling, "WindINERTIA: Controlled Inertial Response from GE Wind Turbine Generators", 45th Annual Minnesota Power Systems Conference, Minneapolis, MN, November 2009. 